\title{
Bibliografia sobre comunicação e educação
}

Ismar de Oliveira Soares"

Professor Titular do Departamento de Comunicações e Artes da ECA/USP.

Coordenador do Núcleo de Comunicação e Educação (NCE) ${ }^{* * *}$.

Membro do Pontifício Conselho para as Comunicações Sociais (Vaticano 2001-2009).

Cordenador do Projeto Mídias na Educação, do MEC, para o Estado de São Paulo

E-mail: ismarolive@yahoo.com

SANTOS, Gislene Aparecida (Org.). Coleção percepções da diferença: negros e brancos na escola. São Paulo: Terceira Margem. 10 volumes. 2009.

A obra analisa as diversas formas comunicacionais adotadas pela sociedade brasileira na abordagem do grupo étnico negro e com ampla repercussão no ambiente da escola. Com caráter educomunicativo, a coleção foi dividida em dez volumes, escritos por especialistas de diferentes áreas, e os títulos foram inspirados em situações detectadas no cotidiano escolar: 1. Percepções da diferença; 2. Maternagem: quando o bebê pede colo; 3. Moreninho, neguinho, pretinho; 4. Cabelo bom. Cabelo ruim; 5. Professora, não quero brincar com aquela negrinha; 6. Por que riem da África?; 7. Tímidos ou indisciplinados?; 8. Professora, existem santos negros? Histórias de identidade religiosa negra; 9. Brincando e ouvindo histórias; 10. Eles têm a cara preta! Conforme a organizadora da coleção, Gislene Aparecida dos Santos - professora da Universidade de São Paulo -, o objetivo do livro é servir de suporte didático para professores e profissionais da Educação Infantil e do Ensino Fundamental que muitas vezes não sabem como agir diante da percepção das diferenças feitas pelos alunos, não impedindo que tais situações se transformem em algo discriminatório. Para Gislene, lidar com as diferenças implica uma predisposição interna para repensarmos nossos valores e possíveis preconceitos. Os volumes da Coleção chamam a atenção para os momentos em que as diferenciações ocorrem em sala de aula, quando podem se tornar discriminatórias, e sugerem formas de ação para os professores.

A obra é ilustrada com desenhos de Marcelo De Salete e Zulmira Gomes Leite, com projeto gráfico de Jorge Kawasaki, permitindo ao professor o uso de recursos visuais ao abordar o tema étnico.

GHEDINI, Fred. Nas ondas sonoras da comunidade: a luta pelas rádios comunitárias no Brasil. São Paulo: Global e Ação Educativa, 2009.

O livro apresenta a rádio comunitária como promotora da democratização da comunicação no país, capaz de abrir oportunidade de profissionalização

* Colaboraram: Karla Isabel de Souza e Ricardo Alexino Ferreira.

** O NCE localiza-se na Av. Prof. Lúcio Martins Rodrigues, 443 - bloco 9, sala 8 - Cidade Universitária - CEP 0558-900 - São Paulo/SP - Tel.: (11) 3091-4784. E-mail: nce@ edu.usp.br. 
comunicação \& educação • Ano XV • número 2 • maio/ago 2010

para os jovens. No primeiro capítulo, trabalha a diferença entre rádios comunitárias e as denominadas rádios livres. Fala do cotidiano de alguns radialistas e do papel que desenvolvem nas comunidades e nos movimentos sociais, em especial no MST - Movimento dos Sem Terra. No segundo capítulo, o livro conta, em detalhes, a história das rádios comunitárias na Europa, nas Américas, na África e, em especial, no Brasil. Comenta que, para garantir seus espaços, os radialistas comunitários lutaram, na Europa, contra o monopólio estatal, enquanto no Brasil colocaram em questão a iniciativa privada monopolizada. No terceiro capítulo, é destacada a criação da Abraco (Associação Brasileira de Radiodifusão Comunitária). Já no capítulo quarto, são mostrados os aspectos positivos e negativos da Lei n. 9.612, de fevereiro de 1998, que instituiu o serviço de radiodifusão comunitária. Por fim no quinto capítulo, o livro analisa o que ainda falta para as rádios comunitárias se desenvolverem no caminho da democratização da radiodifusão brasileira. Como desafios, aponta a digitalização do sinal de transmissão, a função da internet, a potencialidade do celular e o papel desenvolvido na escola com a educomunicação. Neste item, lembra o projeto Educom.radio que levou a linguagem radiofônica como ferramenta pedagógica num projeto implantado a partir de convênio entre o NCE (Núcleo de Comunicação e Educação) da USP (Universidade de São Paulo). No final, o livro sugere livros, páginas da internet, filmes, obras e leis para serem consultados sobre o tema.

MODÉ, Giovanna; PRAZERES, Michelle. Um mundo de mídia: diálogos sobre comunicação e participação. São Paulo: Global e Ação Educativa, 2009.

O livro se apresenta como um subsídio para projetos de educação para a comunicação, uma das áreas do campo da educomunicação. Nesse sentido, trabalha na perspectiva de oferecer material para debates com grupos de jovens, tomando como base atividades desenvolvidas com secundaristas, em oficinas de leitura crítica dos meios de comunicação. No primeiro capítulo, As muitas mídias, os autores relatam a história dos meios de comunicação, abordando, ao final, o tema do direito à comunicação. O segundo capítulo, A mídia tem dono, fala da relação entre o que é público e o que é privado no mundo da mídia, finalizando com uma proposta de debate sobre a democratização dos meios no Brasil. Já o terceiro capítulo, Mídia em transe, levanta uma discussão sobre a convergência que as TICs possibilitaram, advertindo, contudo, para a dificuldade de acesso da população brasileira. Apresenta, ao final, as possibilidades oferecidas pela rádio e televisão digitais. No capítulo quarto, Você aparece na mídia?, o livro discute sobre quem são as pessoas que aparecem na mídia e questiona o leitor quanto a sua representatividade. O tema do jornalismo é abordado e exemplos de construção de imagens e de ideias são discutidos, privilegiando a questão da influência da mídia sobre o jovem. O quinto capítulo, Para mudar a mídia, traz os trabalhos já desenvolvidos 
Bibliografia sobre comunicação e educação • Ismar de Oliveira Soares

em busca da democratização e insiste na comunicação desenvolvida por meios alternativos e comunitários. Para concluir, há depoimentos de jovens produtores e uma lista de livros sugeridos para aprofundamento dos temas abordados.

CUNHA, Maria Zilda da. Na tessitura dos signos contemporâneos: novos olhares para a Literatura Infantil e Juvenil. São Paulo: Paulinas, 2009.

Pela via da semiótica peirceana, a autora se aventura ao exercício de um novo olhar sobre a Literatura Infantil e Juvenil, assumida como arte. A proposta da obra é dimensionar o jogo de literatura e de seus interpretantes. As questões fundamentais tratadas dizem respeito à relação entre texto, linguagens e leitura. O livro explora, dessa forma, as diversas linguagens construtoras da obra literária para a infância e a juventude, propondo maneiras de dialogar com livros infantis originários de outras culturas de língua portuguesa.

Em três capítulos (O conhecimento estético e a escola; Alguns conceitos simples e aplicáveis a qualquer assunto; e Matrizes da linguagem e pensamento, as categorias do estético na Literatura Infantil e Juvenil), o livro discute a contribuição da semiótica, trabalhando com conceitos como estética, signos, linguagem e pensamento, linguagem sonora e visual, narração e dissertação. Ao longo dos capítulos, a autora aponta para a natureza híbrida das linguagens, chegando a analisar os efeitos da hipermídia. Apresenta, finalmente, três paradigmas que são vetores de formas na produção da linguagem humana. O primeiro é o modo de produção artesanal das linguagens verbal, visual e sonora; o segundo é o processo de produção midiatizado pela tecnologia; e o terceiro, são as produções derivadas de matrizes numéricas, a virtualidade e a simulação. Atento ao tema da educação, o livro expõe, logo no primeiro capítulo, as funções deste gênero de produção cultural no âmbito do ensino. A discussão se inicia levantando o que a escola oferece sobre o conhecimento estético, a relação da imaginação com a literatura e como sua produção se processa, para concluir que a concepção de literatura deve estar presente na escola como um bem a ser usufruído, sem nenhuma visão utilitarista.

MALDONADO, A. Efendy; FRAGOSO, Suely. A internet na América Latina. Porto Alegre: Editoras Unisinos e Sulina, 2009.

O livro é uma coletânea que reúne quatorze especialistas em comunicação digital de Argentina, México e Brasil. Seu objetivo é apresentar sínteses de investigações de referência sobre a problemática da configuração e usos da internet nos três países de maior produção científica no subcontinente e que concentram $59 \%$ da população da região. No primeiro capítulo, os organizadores exibem um panorama de conjunto sobre a internet na América Latina. Na continuação, Delia Crovi, da UNAM-México trata sobre Internet, a aposta na diversidade, problematizando aspectos socioculturais de sua introdução e perspectivas. No terceiro capítulo, Sérgio Amadeu aborda Tecnologias da colaboração: o software livre na América Latina, questão crucial para o desenvolvimento 
comunicação \& educação • Ano XV • número 2 • maio/ago 2010

científico, a liberdade política e a sustentabilidade econômica das nossas sociedades. No quarto capítulo, Adilson Cabral Filho e Guttemberg Coutinho argumentam sobre a Web 2.0: Caminhos e desafios no desenvolvimento da internet, mostrando possibilidades e necessidades das reconfigurações digitais. No quinto capítulo, Octavio Islas, do Instituto Tecnológico de Monterrey, revela Apontamentos relativos ao perfil sociodemográfico dos usuários de internet no México (20022007). No sexto capítulo, um grupo de pesquisa da Universidade de Córdoba, Argentina, coordenado por Maria Cristina Mata, traz o texto Políticas sobre TICs e configuração da cidadania: análise do caso argentino no período 2002-2006, focando a problemática sociopolítica, perspectiva na qual oferece importantes subsídios de reflexão e ação. À continuação, Juciano Lacerda (UFRN) fala das Políticas de telecentros de acesso público gratuito e sociedade da informação: modelos em conflito, que mostra uma síntese de importantes pesquisas realizadas pelo autor na inter-relação sociedade da informação e propostas de transformação social. Para encerrar o livro, Raúl Fuentes Navarro, do ITESO-México, participa com o texto Mediações acadêmicas e interfaces digitais para a circulação do conhecimento em ciências da comunicação, situando o campo científico na sua reconfiguração digital. O conjunto da obra oferece informação estratégica, sistematizada por alguns dos maiores especialistas em investigação da América Latina, contribuindo para o esclarecimento de aspectos importantes da estruturação do mundo digital na nossa América.

SOUZA, Ronise Motta Pegoraro de. A Libras como gênero na TV. Bauru, SP: Canal6 Editora, 2009.

O livro tem por objetivo verificar a eficácia do sistema Libras (Língua Brasileira de Sinais) como mensagem de comunicação midiática e como gênero televisivo. No Brasil, a inserção de janela com o intérprete de Libras tem sido adotada em propagandas institucionais públicas do poder executivo federal; na comunicação de empresas públicas e de capital misto (Petrobrás, Vale do Rio Doce, Correios e outras); nos comunicados do poder judiciário e nos esclarecimentos sobre as campanhas eleitorais promovidas pelo Tribunal Superior Eleitoral e, finalmente, no horário da propaganda eleitoral gratuita. Também se verifica aumento da utilização espontânea deste recurso de comunicação em programas religiosos, educativos e informativos. Para verificar se o uso do sistema Libras é de fato eficiente, a autora trabalhou com um grupo de adolescentes com idade entre 16 e 17 anos com surdez profunda (congênita ou precoce), pertencente a uma comunidade cultural distinta e que linguisticamente utilizava a Libras para se comunicar. A esses indivíduos foram exibidas propagandas institucionais do governo federal sobre o referendo contra o comércio de armas de fogo e munição no Brasil. Todas as propagandas exibidas tinham a inserção da janela com o intérprete de Libras. A autora aponta, em seu trabalho, a dificuldade de comunicação que o sistema Libras apresenta na televisão, pois nesse formato não se consegue 
Bibliografia sobre comunicação e educação • Ismar de Oliveira Soares

passar todas as informações necessárias para os surdos, comprometendo, e muito, a compreensão da informação. Isso ocorre porque o enquadramento do intérprete de Libras é muito pequeno e quase sempre filmado no plano americano (da cintura para cima), prejudicando a comunicação dos gestos. Ela entende que não se pode adotar um modelo único e implementá-lo no Brasil como um todo, considerando que a dimensão territorial e a diversidade cultural exigem um modelo exclusivo para cada realidade específica. No entanto, compreende que a Libras é um novo gênero televisivo que tende a ter o uso e a língua disseminados na televisão e, também, em outros espaços midiáticos.

CAETANO, Luciana Maria. Dinâmicas para reunião de pais: construindo a parceria na relação escola e família. São Paulo: Paulinas, 2009.

O processo educativo na família e na escola é descrito neste livro como se estivesse em crise. Uma realidade agravada pelo fato de que ambas as instâncias não reconhecem suas responsabilidades neste contexto. O livro é uma proposta para que escola e família se associem na busca da superação dos conflitos em que estão envolvidos e recuperem o processo educativo em sua autenticidade de diálogo intergeracional e interinstitucional. Para tanto, são apresentadas justificativas sobre os problemas que envolvem a relação entre a escola e as famílias, levando o leitor, finalmente, à discussão pontual da obra: a reunião de pais, um momento estratégico de recuperação da autoconfiança das instituições diante das novas gerações, com a sugestão de atividades e dinâmicas de mútuo relacionamento.

MARQUES DE MELO, José (Org). Gêneros jornalísticos no Brasil. São Bernardo do Campo: Editora da Universidade Metodista de São Paulo, 2010.

O livro Gêneros jornalísticos no Brasil reúne 13 textos resultantes de pesquisas de mestrado e doutorado do programa de pós-graduação da Universidade Metodista de São Paulo, lançado nacionalmente no dia 22 de abril de 2010, na cidade do Recife, durante o XI Encontro Nacional dos Professores de Jornalismo, promovido pela Universidade Católica de Pernambuco e pelo Fórum Nacional dos Professores de Jornalismo - FNPJ. Também assina o livro o pesquisador Francisco de Assis, autor de dois textos da coletânea. O enredo é centrado em uma reflexão coletiva acerca de saídas possíveis para a crise por que passa o jornalismo no país. Prefaciado por Cicília M. Krohling Peruzzo, é dividido em duas partes. Na primeira, de estudos gerais, os autores buscam classificar e conceituar os diversos gêneros, formatos e tipos cultivados pela mídia contemporânea. Já na segunda, um conjunto de textos é constituído por análises que desvendam a utilidade potencial do tema, visando à aplicação nas rotinas profissionais. Segundo Marques de Melo, o livro é "uma tentativa de resgatar a identidade jornalística numa conjuntura minada por vaticínios desestabilizadores, apregoando o ocaso do jornalismo, ou sugerindo a passagem 
comunicação \& educação • Ano XV • número 2 • maio/ago 2010

a uma espécie de pós-jornalismo". Os autores convidados por José Marques de Melo são ex-alunos que passaram por suas aulas entre 2004 e 2009. Neste período de quinze anos o organizador de Gêneros jornalísticos no Brasil orientou mais de 10 pesquisas de pós-graduação sobre o tema. Além de Francisco de Assis (Universidade de Taubaté), assinam os textos: Ana Regina Rêgo, Daniela Bertocchi, Guilherme Jorge de Rezende, Janine Marques Passini Lucht, Lailton Alves Costa, Laura Conde Tresca, Maria Isabel Amphilo, Tyciane Cronemberger Viana Vaz e Virgínia Salomão. Trata-se de obra de apoio didático para alunos e professores de Jornalismo, bem como de roteiro útil aos jovens que se iniciam na profissão, mas não tiveram treinamento suficiente no exercício dos gêneros jornalísticos. 